\title{
Calculation on Personal Account Payment Ratio of Pension Insurance of Urban Workers
}

\author{
Li Zhang, Yanan Yang* \\ School of Economics \\ Harbin University of Commerce \\ Harbin, China \\ yynmie@163.com
}

\author{
Wei Wang \\ School of Finance and Public Management \\ Harbin University of Commerce \\ Harbin, China \\ 63993022@qq.com
}

\begin{abstract}
In order to analyze the ratio of personal account payment, the paper made the maximizing personal utility and social welfare as the study perspectives, regarded the urban workers and state-owned enterprises as the research object. By applying the model of personal optimal payment ratio, we calculated the ratio, $10.9 \%$, which was higher than the current level of 2.19 percent, carried out the feasibility analysis and sensitivity analysis. Furthermore, we concluded it is feasible to increase the personal payment ratio moderately to reach government needs and social development.
\end{abstract}

Keywords-urban workers; personal account; personal payment ratio; pension insurance

\section{INTRODUCTION}

With the development of Chinese economy and aging of population, the pension payment ratio has become the key issue of the reform of the pension insurance system. Aiming at the research on the payment ratio of pension insurance of urban workers, many scholars at domestic and abroad have studied from different angles. The study of foreign payment ratio is mainly embodied in the concept of payment and the forecast of future payment ratio, and they consider that the State should implement the pension insurance system combined with the pay-as-you-go system and fund accumulation system, propose the optimal payment ratio model under the pay-as-you-go system, and find that optimum payment ratio is related to the productivity, the ratio of population growth and the marginal product of capital [1-2]. The research on the domestic pension insurance is mainly embodied in the calculation of the social pension insurance payment ratio. Scholars have studied the internal factors such as pension substitution ratio and system maintenance ratio, analyzed the external factors such as the effective solution of historical debts, enriching the source of funds and raising the ratio of payment, raising the fund management. And they propose that China should reduce unit payment ratio and increase personal payment ratio, but the drastic reduction is not desirable [3-6]. This paper mainly based on the Thirteenth Five-year plan which propose to reduce the social pension payment ratio, calculated the personal account payment ratio of pension insurance of urban workers from the perspective of welfare maximization.

This research was financially supported by National Social Sciences Fund under grant 13AZD071, 14BJY032, Humanities and Social Sciences Fund of Ministry of Education under grant 12YJC790190, Postdoctoral Scientific Research Initiation under grant LBH-Q14094, LKY-2016jx-09 of CALSS in China.

\section{Optimal Payment Ratio Model of PENSION InSURANCE PERSONAL ACCOUNT OF URBAN WORKERS}

The pension insurance of urban workers is aimed at providing the social security after retirement, and satisfying every employee's needs, so we can consider that the optimal payment ratio of pension insurance from the perspective of personal utility and social welfare maximization. Assuming that the economy has three main bodies, employees, retirees and the government, the goal of workers is the maximization of life cycle utility, the goal of government is the maximization of social welfare, while the payment ratio which satisfy employee's life cycle utility and social welfare maximization is the optimal ratio.

\section{A. Objective Function of Workers and Government}

\section{1) Objective function of workers}

Assuming that the personal utility is its consumption level function, the payment and prostrations of pension insurance change the consumption composition of worker's working period and retirement period, thus further influence their life cycle utility. Therefore, the function of consumption should be described before the objective function of workers is constructed. For simply research, this paper did not consider saving, therefore, under the system of basic pension insurance, the employee's consumption of working period equals the gross income subtract the personal account payment and the social co-ordination payment, the consumption of retirement period is composited by the personal account pension and the social co-ordination pension[7].

Under the system of basic pension insurance, the consumption of personal employees in $\mathrm{t}$ period is as following (1).

$$
C_{t, 1}=\left\{(1-\alpha-\beta) w_{t} A_{t}\right\}
$$

Where $\mathrm{t}$ is birth period, $C_{t+1}$ is Consumption of single workers during $\mathrm{t}$ period, $\alpha$ is personal payment ratio, $\beta$ is unit payment ratio, wt is unit effective labor of t period, $A_{t}$ is effective work of personal workers. 
The consumption of $t$ period of personal workers in the $t+1$ period is as following (2).

$$
C_{t+1,2}=\left\{\beta \lambda(1+g)(1+e) w_{t+1}+\alpha\left(1+r_{t}\right) w_{t}\right\} A_{t}
$$

Where $\mathrm{C}_{\mathrm{t}+1,2}$ is the consumption during $\mathrm{t}+1$ period of personal workers who retire in $t$ period, $\lambda$ is ratio coefficient of wages, $\mathrm{g}$ is population growth ratio, e is effective labors growth ratio, $r_{t}$ is interest ratio level in $\mathrm{t}$ period.

Assuming utility functions as logarithmic form $U(C)=L n C$, the life cycle utility of a single worker in $t$ period is as following (3).

$$
U_{t}=U_{1}\left(C_{t, 1}\right) v U_{2}\left(C_{t+1,2}\right)
$$

Where $v$ is the discount factor of personal future utility, $\mathrm{U}_{1}$ is utility of working, $\mathrm{U}_{2}$ is utility of retirement.

\section{2) Objective Function of Government}

The government is concerned about the interests of workers and retirees in the same period, and therefore, the objective function of government include the utility of workers and retirees, the goal is aim at maximizing social welfare.

Assuming the population of the $\mathrm{t}-1$ period is $\mathrm{L}_{\mathrm{t}-1}, \mathrm{t}$ period is $\mathrm{L}_{\mathrm{t}}$, and the government target function is as following (4).

$$
W_{t}=L_{t}\left\{U_{1}\left(C_{t, 1}\right)+v U_{2}\left(C_{t+1,2}\right)\right\}+L_{t-1} U_{2}\left(C_{t, 2}\right)
$$

\section{B. Model of Personal Optimal Ratio}

According to (3) and (4), we can get the model is as following (5).

$$
\alpha=\frac{a}{1-a} \cdot \frac{v(1+g)(1+e)}{\lambda(1+e)[1+v(1+g)]-v}
$$

Where $\alpha$ is personal optimal ratio, $a$ is elasticity coefficient of capital output, $\mathrm{g}$ is population growth ratio, $v$ is the discount factor of personal future utility, e is effective labors growth ratio, $\lambda$ is ratio coefficient of wages.

\section{Calculations on Personal Account Payment Ratio OF PENSION INSURANCE OF URBAN WORKERS}

\section{A. Data Acquisition and Parameter Selection}

\section{1) Population growth ratio}

Searching from China Statistical Yearbook, we obtained the population growth ratio was $14.39 \%$ in $1990,10.55 \%$ in 1995 , $7.58 \%$ in $2000,5.89 \%$ in $2005,4.79 \%$ in 2010 , and $4.96 \%$ in 2015. Therefore, in views of the aging population in China, the natural population growth ratio is set at $4 \%$.

\section{2) Effective labors growth ratio}

In this paper the effective labor growth ratio equal to urban workers employment growth ratio, searching from the China Statistical Yearbook, we can see that the growth ratio of effective labor is in the range of $2.72 \%$ to $4.43 \%$, so take the average of 1996-2015 years, the effective labor growth ratio is $3.74 \%$.

\section{3) Discount factor of personal future utility}

The discount factor is closely related with the interest rate is as following (6).

$$
v=1 /(1+r)^{n}
$$

Where $\mathrm{n}$ is time interval between future and current, $\mathrm{r}$ is interest rate. Searching from China Statistical Yearbook, $r$ is set at $4 \%$. Assuming workers work at 20 years, and retire at 60 years, maximum payment age is 40 years, so the discount factor of personal future utility $v=0.2083$.

\section{4) Elasticity coefficient of capital output}

According to production function of Cobb-Douglas, the statistic value of industrial gross output, investment, and employee gross wages of state-owned enterprise from 1991 to 2014 can be returned to the contribution ratio of capital factor and labor factor of state-owned enterprises in China, the data of gross output value, investment and employee gross wages derived from Chinese Statistical Yearbook. After the logarithmic transformation of production function of CobbDouglas, we can obtained the function is as following (7).

$$
\begin{gathered}
\operatorname{Ln} Y=0.571885+0.321485 \operatorname{LnK}+0.779391 \operatorname{LnL} \\
(T)(0.977605) \quad(1.231699) \quad(2.288825) \\
R^{2}=0.982956 F=576.7001(p=0.0000) D W=0.511336
\end{gathered}
$$

According to the regression results, we can set the elasticity coefficient of capital output $\mathrm{a}=0.32$.

\section{5) Ratio coefficient of wages}

In this paper, the ratio coefficient of wage in various regions in 2015 as an example, in which the ratio coefficient of wage is the ratio of the average wage of urban in each region and the average wage of the national. Searching from China Statistical Yearbook, we can obtain ratio coefficient of wages of 31 provinces and cities in 2015, as well as Q which is the number of urban workers, the results as shown in table 1 .

TABLE I. RATIO COEFFICIENT OF URBAN WORKERS' WAGE AND NUMBER OF URBAN WORKERS IN 2015

\begin{tabular}{|c|c|c|}
\hline East & $\lambda$ & $\mathbf{Q}$ \\
\hline BJ & 1.795773 & 777.3 \\
\hline TJ & 1.29117 & 294.8 \\
\hline HB & 0.820922 & 643.6 \\
\hline SH & 1.760048 & 637.2 \\
\hline JS & 1.067178 & 1552.1 \\
\hline ZJ & 1.074788 & 1083.4 \\
\hline FJ & 0.929049 & 663.1 \\
\hline SD & 0.923278 & 1236.7 \\
\hline GD & 1.055376 & 1948.0 \\
\hline HN & 0.928598 & 100.4 \\
\hline West & $\lambda$ & $\mathbf{Q}$ \\
\hline \multicolumn{2}{r}{}
\end{tabular}




\begin{tabular}{|c|c|c|}
\hline \multicolumn{3}{|c|}{ TABLE 1, cont. } \\
\hline NMG & 0.921101 & 298.3 \\
\hline GX & 0.854149 & 405.4 \\
\hline CQ & 0.976043 & 415.6 \\
\hline SC & 0.949798 & 795.5 \\
\hline GZ & 0.962469 & 307.5 \\
\hline YN & 0.84741 & 414.7 \\
\hline XZ & 1.577472 & 33.4 \\
\hline SX & 0.886585 & 511.8 \\
\hline GS & 0.853504 & 261.8 \\
\hline QH & 0.984862 & 62.7 \\
\hline NX & 0.973416 & 73.1 \\
\hline XJ & 0.969176 & 317.2 \\
\hline Central & $\lambda$ & $\mathbf{Q}$ \\
\hline SX & 0.835142 & 440.3 \\
\hline AH & 0.888923 & 521.7 \\
\hline JX & 0.8211 & 465.3 \\
\hline HN & 0.731964 & 1125.9 \\
\hline HB & 0.876477 & 712.3 \\
\hline HN & 0.844073 & 579.1 \\
\hline Northeast & $\lambda$ & $\mathbf{Q}$ \\
\hline LN & 0.84367 & 618.4 \\
\hline JL & 0.831192 & 325.1 \\
\hline HLJ & 0.788035 & 433.5 \\
\hline National & $\lambda$ & $\mathbf{Q}$ \\
\hline & 1 & 18062.5 \\
\hline
\end{tabular}

B. Calculation on Personal Account Payment Ratio of Pension Insurance of Urban Workers

The data of the above indexes are added to the formula (5), and the results are calculated by Eviews8.0, as shown in table 2

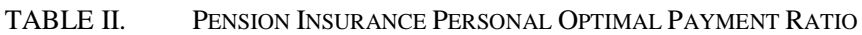
OF URBAN WORKERS

\begin{tabular}{|l|l|l|l|l|c|}
\hline East & \multicolumn{1}{c|}{$\alpha$} & West & \multicolumn{1}{c|}{$\alpha$} & Central & $\alpha$ \\
\hline BJ & $4.99 \%$ & NMG & $10.77 \%$ & SX & $12.15 \%$ \\
\hline TJ & $7.23 \%$ & GX & $11.81 \%$ & AH & $11.25 \%$ \\
\hline HB & $12.41 \%$ & CQ & $10.04 \%$ & JX & $12.41 \%$ \\
\hline SH & $5.10 \%$ & SC & $10.37 \%$ & HN & $14.36 \%$ \\
\hline JS & $9.02 \%$ & GZ & $10.21 \%$ & HB & $11.44 \%$ \\
\hline ZJ & $8.95 \%$ & YN & $11.93 \%$ & HN & $11.99 \%$ \\
\hline FJ & $10.65 \%$ & XZ & $5.76 \%$ & & \\
\hline SD & $10.74 \%$ & SX & $11.28 \%$ & Northeast & $\alpha$ \\
\hline GD & $9.09 \%$ & GS & $11.83 \%$ & LN & $12.00 \%$ \\
\hline HN & $10.66 \%$ & QH & $9.93 \%$ & JL & $12.22 \%$ \\
\hline & & NX & $10.07 \%$ & HLJ & $13.07 \%$ \\
\hline & & XJ & $10.12 \%$ & Average & $10.19 \%$ \\
\hline
\end{tabular}

As can be seen from table 2, under the premise that the other related parameters are fixed, the optimal payment ratio of personal account shows a negative correlation with different wage levels in different regions. The ratio of the optimal payment is lower while the wage level is higher. The ratio of the optimal payment is higher while the wage level is lower. This is because in the same level of pension, the pension insurance costs of the area of higher wages accounted for a small proportion of the total wages, the pension insurance costs of the area of lower wages accounted for a big proportion of the total wages. Because there are different numbers of employment in different regions, the weight of payment ratio are different. This paper chose the number of urban workers of east, west, central and northeast as the weight. The weighted average value is $10.19 \%$. $8 \%$ which is the current personal payment ratio in China is lower than the optimal ratio of 2.19 percent.

\section{FeAsibility AnAlysis of PeRsonal Optimal PAyMENT RATIO}

Part of the wage income for the consumption of current period, part of the long-term consumption for the formation of savings. The workers' pension insurance should not exceed its voluntary savings. Otherwise savings will affect the consumption of current period, so we can determine the upper limit of personal payment ratio through the analysis of savings. Assuming that the per capita income of urban households is $\mathrm{Y}$, the total consumption per capita in the working period is $\mathrm{C}$, and the fixed consumption per capita is $\mathrm{C}_{0}$, and the marginal propensity to consume is $\mathrm{c}$. The consumption formula in western economics is $C=C_{0}+c Y$. Assuming that $\mathrm{A}$ is the upper limit of personal payment ratio, and $\mathrm{W}$ is the average wage of workers, the formula for calculating the upper limit of personal payment ratio is as following (8).

$$
A_{\text {Upper }}=(\mathrm{Y}-\mathrm{C}) \div \mathrm{W}=\left(\mathrm{Y}-\mathrm{C}_{0}-\mathrm{cY}\right) \div \mathrm{W}=\left[(1-\mathrm{c}) \times \mathrm{Y}-\mathrm{C}_{0}\right] \div \mathrm{W}
$$

This paper took the related data of urban residents from 2006 to 2015 as research object, the per capita consumption expenditure of urban household and the average wages of urban worker are derived from Chinese Statistical Yearbook. The results were calculated by Eviews8.0, we can obtained the following measurement regression equation is as following (9).

$$
\begin{aligned}
& C=1801.715+0.550496 Y \\
& F=12756.16 P=0.0000 R^{2}=0.999373
\end{aligned}
$$

By regression results, $\mathrm{C} 0$ which is fixed per capita consumption is 1801.715 and $\mathrm{c}$ which is marginal consumption tendency is 0.550496 . The value of $\mathrm{C}_{0}, \mathrm{c}$, and the $\mathrm{W}$ were added to the formula (8), and the Eviews8.0 calculated the upper limit of personal payment ratio is as following table 3 .

TABLE III. UPPER LIMIT OF THE RATIO OF URBAN WORKERS PENSION INSURANCE IN 2006-2015

\begin{tabular}{|c|r|r|r|r|r|}
\hline Year & $\mathbf{2 0 0 6}$ & $\mathbf{2 0 0 7}$ & $\mathbf{2 0 0 8}$ & $\mathbf{2 0 0 9}$ & $\mathbf{2 0 1 0}$ \\
\hline Upper & $17.90 \%$ & $18.77 \%$ & $19.82 \%$ & $20.31 \%$ & $20.70 \%$ \\
\hline Year & $\mathbf{2 0 1 1}$ & $\mathbf{2 0 1 2}$ & $\mathbf{2 0 1 3}$ & $\mathbf{2 0 1 3}$ & $\mathbf{2 0 1 4}$ \\
\hline Upper & $20.94 \%$ & $21.48 \%$ & $22.06 \%$ & $22.30 \%$ & $22.67 \%$ \\
\hline
\end{tabular}

As can be seen from table 3 , in the target year of the investigation, although the upper limit of personal payment ratio of each year are different, but there is a clear upward trend. The upper limit increased from $17.9 \%$ in 2006 to $22.67 \%$ in 2015. This is because with the economic development, the Engel coefficient continues to decrease, the per capita consumption expenditure accounted for the proportion of total per capita income is relatively low, and therefore the proportion which can be used to pay the pension insurance costs are increased. We can see the proportion of payment ratio from 2006 to 2015 years, the limit values of personal payment ratio of pension insurance are much higher than $8 \%$ which is the specified standard, of course, in reality, the moderate 
personal payment ratio cannot increase to the upper limit, but the conclusion can theoretically indicate that pension insurance payment ratio has increased space.

\section{SENSITIVITy ANALYSIS OF OPTIMAL PAYMENT RATIO}

This paper assumed that some index data are constant, but the reality is not so. In order to test the robustness of the above results, this paper made a sensitivity analysis on the natural growth ratio of $g$, the effective labor growth ratio of e and the capital elasticity coefficient of a, and the results were shown in table 4. By table 4, the population natural growth ratio of $\mathrm{g}$ with the personal optimal payment ratio are positive change, $g$ increase or decrease 0.001 , resulting in $\alpha$ increase or decrease $0.08 \%, \mathrm{~g}$ increase or decrease 0.002 causes $\alpha$ increase or decrease $0.16 \%$. Effective labor growth ratio of e with the personal optimal payment ratio are negative change, e increase or decrease 0.01 causes $\alpha$ decrease or increase $0.21 \%$, e increase or decrease 0.02 results in decrease or increase $0.41 \%$ and $0.43 \%$. The capital elasticity coefficient of a with the personal optimal payment ratio are positive change, a increase or decrease 0.01 causes $\alpha$ increase or decrease $4.79 \%$ and $4.4 \%$, a increase or decrease 0.02 causes $\alpha$ increase or decrease $9.6 \%$ and $8.81 \%$.

TABLE IV. SENSITIVITy ANALysis of THE Optimal Payment Ratio of URBAN WORKERS PENSION INSURANCE

\begin{tabular}{|l|l|l|l|l|l|}
\hline Parameters & \multicolumn{1}{|c|}{$\mathbf{n}=\mathbf{4 0}$} & Parameters & $\mathbf{n}=\mathbf{4 0}$ & Parameters & $\mathbf{n}=\mathbf{4 0}$ \\
\hline $\mathrm{g}=0.2 \%$ & $0.16 \%$ & $\mathrm{e}=1.74 \%$ & $0.43 \%$ & $\mathrm{a}=0.3$ & $8.81 \%$ \\
\hline $\mathrm{g}=0.3 \%$ & $0.08 \%$ & $\mathrm{e}=2.74 \%$ & $0.21 \%$ & $\mathrm{a}=0.31$ & $4.40 \%$ \\
\hline $\mathrm{g}=0.4 \%$ & 0 & $\mathrm{e}=3.74 \%$ & 0 & $\mathrm{a}=0.32$ & 0 \\
\hline $\mathrm{g}=0.5 \%$ & $0.08 \%$ & $\mathrm{e}=4.74 \%$ & $0.21 \%$ & $\mathrm{a}=0.33$ & $4.79 \%$ \\
\hline $\mathrm{g}=0.6 \%$ & $0.16 \%$ & $\mathrm{e}=5.74 \%$ & $0.41 \%$ & $\mathrm{a}=0.34$ & $9.60 \%$ \\
\hline
\end{tabular}

From table 4, the optimal payment ratio is indeed influenced by $g$, e and a. And the sensitivity of personal optimal payment ratio is weaker to the change of $g$ and e, and the sensitivity to a change is stronger. Therefore, the rationality of the value of these variables needs to be fully considered before adjusting the optimum payment ratio.

\section{CONCLUSIONS}

Based on the maximization of personal utility and social welfare, the paper calculated the personal optimal payment ratio of pension insurance of urban worker with a weighted average of $10.19 \%$, above the current level of 2.19 percent. Through applying the feasibility and sensitivity analysis of the optimal payment ratio, the measurement of the optimum payment ratio is influenced by the change of the related index, and it is feasible to increase the ratio of personal payment ratio. This paper calculated the optimal payment ratio of pension insurance, referring to the research results of other scholars, assuming that some data indicators are fixed, therefore only consider the finite parameters, in the follow-up study we will be further comprehensive consideration, precise positioning, refinement analysis of relevant parameters, in order to obtain more reasonable personal payment ratio of pension insurance.

\section{REFERENCES}

[1] Amy Rehder, "Social security benefit uncertainty under individual accounts", Contemporary Economic Policy, 2005, No. 23, pp.1.

[2] Thomas R.Michel, "Duncan k.Foley, Social security in a classic growth model", Science Direct, 2001, No. 6 .

[3] Wu Shurong, "Brief discussion on the causes of urban workers pension insurance fund gap and countermeasures", Public Administration, 2013, No. 12, pp. 191.(in Chinese)

[4] Sun Yongyong, LI Weihan, "From the rate of urban workers to see the basic old-age insurance system reform", China Population Science, 2014, No. 5, pp.67-78.(in Chinese)

[5] Xian Mihua, "Urban workers basic pension insurance fund revenue and expenditure of the status quo, problems and countermeasures", Technological Entrepreneurship, 2015, No. 16, pp. 18-20.(in Chinese)

[6] Bian Shu, Mu Huaizhong, "Analysis of optimal contribution rate of personal account in Liaoning pension based on welfare maximization", Population Development, 2009, No.4, pp.93.(in Chinese)

[7] Niu Shuzhen, Liu Fang, "Research on optimal contribution rate based on China basic pension insurance system", Business Research, 2007, No. 9, pp. 65-66. (in Chinese). 